\title{
Web-based knowledge management system: linking smart metering to the future of urban water planning
}

Published in:

Stewart, R.A. Willis, R.M., Giurco, D., Panuwatwanich, K., and Capati, B. (2010) "Web-based knowledge management system: linking smart metering to the future of urban water planning." Australian Planner, Volume 47, Number 2, 66-74.

\section{List of authors:}

R.A. Stewart ${ }^{1}$, R.M. Willis ${ }^{2}$, D. Giurco ${ }^{3 *}$, K. Panuwatwanich ${ }^{4}$, G. Capati ${ }^{5}$

${ }^{1}$ Griffith School of Engineering, Griffith University, QLD, Australia Email: r.stewart@griffith.edu.au

${ }^{2}$ Griffith School of Engineering, Griffith University, QLD, Australia Email: r.willis@griffith.edu.au

${ }^{3}$ Institute for Sustainable Futures, University of Technology, NSW, Australia Email: Damien.Giurco@uts.edu.au

${ }^{*}$ Corresponding author

${ }^{4}$ Griffith School of Engineering, Griffith University, QLD, Australia

Email: k.panuwatwanich@griffith.edu.au

${ }^{5}$ Infrastructure Planning, Gold Coast Water, QLD, Australia

Email: gcapati@goldcoastwater.com.au 


\section{Web-based knowledge management system: linking smart metering to the future of urban water planning}

\section{ABSTRACT}

The planning of cities and their water supplies are intertwined. This paper explores the potential role of smart metering for the future of water planning and management in Australian cities. Smart meters for electricity are being rolled out nationally, and while smart meters for water are not yet being implemented at such a scale, they have the capacity to deliver increasing data to planners and residents about patterns of water use. To translate this data to useful information, a Web-Based Knowledge Management System (WBKMS) is proposed, which integrates smart metering, end use water consumption data, wireless communication networks and information management systems in order to provide real-time information on how, when and where water is being consumed for the consumer and utility. Summary data from the system will also be of interest to architects, developers and planners, seeking to understand water consumption patterns across stratified urban samples. An overview of the challenges for developing the WBKMS and an associated research agenda to address current knowledge gaps concludes the paper.

Keywords: end use water consumption; knowledge management; urban water planning; water resource management; smart metering

\section{INTRODUCTION}

Prosperous cities must be able to respond to future pressures from increasing populations, climate variability and climate change while maintaining adequate water services for residents and businesses. A study by Birrell et al. (2005) on the impact of demographic change and urban consolidation on domestic water use in Australian cities revealed that, during 2001-2031, water demand in the major cities can be expected to increase by an average of $37 \%$. Based on dwindling water supplies (due to droughts and changing rainfall patterns) and projected increasing demands, the management of water resources has become a major concern for residential consumers, industry and all levels of government. Many Australian cities have recently embraced a combination of initiatives to reduce demand (e.g. installing efficient appliances and undertaking water recycling) and have begun increasing sources of supply through the installation of rainwater tanks and the construction of 
desalination plants. Such changes to water supply sources and patterns of demand mean smarter approaches to urban water management are required to achieve a sustainable water future; the era when urban water planning focussed only on how to build and supply water has passed. This ever-changing water supply system demands adaptive and innovative management fed by robust information.

Currently, governments and public utilities are investing significant funds in the development and implementation of water strategies to ensure future water demands are met. Demand management strategies include water restrictions, rebate programs for water efficient devices, water efficiency labelling, water conservation or education programs and pressure and leakage management (Inman and Jeffrey, 2006). Source substitution or 'fit for use' water involves replacing specified potable end uses such as toilet flushing and irrigation with recycled, grey or storm water. Water savings achievable from such programs are calculated through a variety of assumptions but, once in place, limited consideration is given to determining the actual water savings associated with these strategies.

Each of the aforementioned diversified demand management strategies has different potential depending on their scale of implementation as demonstrated in Figure 1. The size of the 'bubble' in Figure 1 represents a measure of relative savings potential at the relevant scale (either smaller or larger), with more than half of these measures depending on smart metering technology to achieve or effectively monitor their potential. For example, to implement time of use or drought pricing $^{1}$, a real-time signal on water use is needed for consumers and utilities. Smart meters, which can discern end uses, can also play an important role in detecting leaks in existing dwellings (Britton et al., 2008).

\section{[Insert Figure 1]}

The advent of advanced water metering, logging and wireless communication technologies has enabled the dynamic accurate measurement and data transfer of useful end use water consumption information (e.g. time and quantity of water use in a shower). An example of the water end use break down in litres/person/day (L/p/d) and percent (\%) for a Gold Coast sample is shown in Figure 2. Further real-time data

\footnotetext{
${ }^{1}$ Drought pricing could replace water restrictions as a means of reducing outdoor water use during drought by charging higher prices during times of water scarcity. It could be structured to apply only above an allocated quota needed for basic household uses, meaning householders could still water their garden, but would pay a premium for doing so.
} 
of this nature would help planners and developers understand everyday water use and consumer behaviour, and their spatio-temporal variability. Readers are referred to Willis et al. (2009) for more information on the end use analysis process and summary outputs from this procedure.

\section{[Insert Figure 2]}

In order to improve long term forecasting, more data and information should be collated on the effectiveness and sustainability of demand management techniques (Chambers et al., 2005). This requires an innovative water consumption knowledge management system to enhance the management of the current water resource issues.

While smart metering technologies are becoming available and are being implemented in an improvised manner, no water organisations on the international stage have developed a robust system which can assist both water users (i.e. households) and managers (i.e. water utilities, architects, planners and state authorities) through empowerment with a range of comprehensive, and instantly available reports, on water consumption patterns and comparisons with others (e.g. a householder's water use is higher than a comparable household for shower use). Moreover, researchers have, to date, failed to proactively provide a roadmap for the coherent adaptation of this wide range of available technologies. Nor have they provided the architecture of a suitable web-based information transfer platform. Both of these could be used to rapidly advance current outdated urban water resource management practices.

The aims of this paper are to: provide an overview of contemporary issues in water planning, in particular smart metering; and, to show how the development of a WebBased Knowledge Management System (WBKMS) would enable the data, collected by smart metering, to be used by customers and utilities for improved planning across all scales - from within single detached households to a city-wide scale.

\section{SMART METERING}

The concept of smart metering embraces two distinct elements: meters that use new technology to capture water use information; and, communication systems that can capture and transmit water use information as it happens, or almost as it happens 
(NYSERDA, 2003). Smart water meters essentially perform three functions; they automatically and electronically capture, collect and communicate up-to-date water usage readings on a real-time (or nearly real time) basis (Idris, 2006). The information is available as an electronic signal, which can be captured, logged and processed like any other signal (Britton et al., 2008). In addition, today's data distribution technologies (e.g. using mobile phone technology at the meter / data logger) make it possible to bring this signal readily to any computer (Hauber-Davis and Idris, 2006) and to a central point for analysis or to a website for customer viewing. When interrogated, the data logger downloads the water consumption data to a server, giving a value of water consumption of the required period (Idris, 2006). In this way smart meters can communicate the captured data to a broad audience, e.g. utility managers, consumers and facility authorities. Figure 3 illustrates the components of a typical smart meter set-up for a residential household. It should be noted that the richness of water consumption information derived from a smart metering system is dependent on the water meter's resolution and the data logging frequency. Current generation large scale smart metering implementations utilise affordable standard resolution water meters (i.e. 1 pulse per litre) logging at typically hourly intervals. These current generation smart metering systems provide a range of additional management implications to current practice such as leak detection (see, for example, Britton et al., 2008), time-of-use tariffs and peak demand identification However, future generation systems will offer very high resolution meters (e.g. 72 pulses per litre) dynamically transferring second-by-second data via GPRS to intelligent information systems that produce very detailed, multi-faceted information such as itemised water end use data (see, for example, Willis et al. 2009). Whilst, current generation smart metering systems are acknowledged herein as fit-forpurpose technologies that are currently commercially viable, the researchers have implemented and are working towards a more rapid progression of the latter generation high resolution smart metering systems and the associated urban water management methodologies. Readers should be aware that not all later discussed smart metering benefits are achievable by the large scale citywide implementations of current generation technologies.

In summary, smart metering is an established technology which is now cost-effective enough to be applied in Australia to collect, store and distribute real-time water consumption data (Hauber-Davis and Idris, 2006). An automated meter reading system with this capability provides benefits for both consumers and water authorities for monitoring and controlling water consumption (Britton et al., 2008). 


\section{[Insert Figure 3]}

Beyond consumption data, smart meters in the electricity sector have been identified as offering additional societal benefits including service reliability enhancement, feedback, demand response and new products and services (Neenan and Hemphill, 2008). However, the under-explored question of privacy considerations relating to data ownership and management remains (Mclntyre, 2008). This should be an area of focus for further research.

\section{WEB-BASED KNOWLEDGE MANAGEMENT SYSTEM}

As an extension to the existing architecture of the smart water metering system, the authors propose the development of a WBKMS, which is designed as a powerful tool to support an integrated water conservation management system in order to sustain long term water savings. The WBKMS can actively monitor water consumption and provide real-time information about what, when, where and how water is consumed. The primary functions of the WBKMS include: collecting real-time water consumption data through a smart water metering system; transferring and storing the data into a knowledge repository and analysing the data; and producing a wide range of reports which can be accessed on-line by a broad range of users (e.g. consumers, water utilities, government organisations, developers). Developers would have a particular interest in this information in New South Wales, where the Water Industry Competition Act 2006 allows private sector providers (in addition to the government owned utility) to supply reticulated drinking water, recycled water and sewerage services to residents. The regulation relating to the Act was established in 2008 and two types of licences (or both) can be applied for - a network operator's licence to construct, maintain or operate water industry infrastructure and a retail supplier's licence which must be obtained to supply potable or non-potable water or provide sewerage services by means of water industry infrastructure (IPART, 2008). ${ }^{2}$ The

\footnotetext{
${ }^{2}$ At the time of writing, there are three licence holders for non-potable water infrastructure and one for non-potable retail supply, neither of which are yet operational, however there are current applicants for the provision of sewerage infrastructure and services and in future potable retailers are expected. Residents (for example in a new development) would not receive two separate water sources, rather the government-owned utility would become the default supplier in the event that the private supplier ceased to exist. For further information and data on current licence holders see htpp://www.ipart.nsw.gov.au.
} 
WBKMS will provide tailored analytical tools and reports for each specific group of users. Such a system is available for commercial and industrial customers (Hydroshare, 2009), but has not yet been developed for residential customers and is not pervasive enough throughout the utility to be used for water planning. Figure 4 provides a diagrammatic illustration of the structure of the WBKMS.

\section{[Insert Figure 4]}

One application of the WBKMS allows for individual consumers to log into their userdefined water consumption web page to view their daily, weekly and monthly consumption tables as well as charts on water use patterns for categories of water end use. Moreover, cumulative water billing can be updated daily or even hourly, and on-line alarms will be generated to indicate potential causes for excessive water use (e.g. internal leaks). This will help consumers to take corresponding water saving actions.

This system also enables water utilities to intervene as soon as an exception alarm is raised for end uses such as major water leaks. Leaks going unnoticed for months on end will become a thing of the past (Britton et al., 2008). The analytical report generated by the system will also be able to help utilities to identify the water consumption patterns of different types of consumers. Figure 5 presents an example of analysis on monthly water usage for different groupings of households. As demonstrated by this example, it will be possible to correlate stored demographic data with water consumption patterns, thus enabling deeper understanding of different categories of water users. This type of information will allow water authorities to develop targeted education campaigns relating to conservation and water use, and an opportunity to develop different tariff systems to influence consumption behaviour. The most powerful function of the WBKMS is to transfer water consumption data and information into water consumption knowledge.

\section{[Insert Figure 5]}

It is important to note here that to fully achieve the aforementioned WBKMS functionality, the type of water meter used for the smart metering configuration should ideally be high resolution (e.g. 72 pulses per litre). This type of meter will enable high frequency measurement of water consumption, enabling the disaggregation of hydraulic flow into discrete water end use events (e.g. shower, toilet, garden irrigation etc.). Reinforcing previous statements, smart metering systems with lower resolution meters will still gain many of the benefits from the WBKMS framework presented, but without those related to receiving customer or 
management reports on end use water consumption. Based on the detailed water consumption data and analytical output, future water consumption trends can be forecasted and water conservation opportunities identified, thus ultimately ameliorating the understanding of water consumption behaviours. This rich knowledge can provide additional effective and efficient support for formulating water demand management strategies to reduce consumption. It can also be used to target funds at those that provide the highest water yield savings at the least cost. The linked pathways for metering, planning and management are illustrated conceptually in Figure 6

Figure 6. Specific benefits of the WBKMS for infrastructure planning, demand management and water consumers are discussed in the following section.

[Insert

Figure 6]

\section{DISCUSSION OF BENEFITS}

\section{Infrastructure planning and management}

Water and wastewater infrastructure planning and management are primarily focused on long-term strategic planning including: developing strategies for holistic catchment water management; system modelling; development assessment and conditioning; priority infrastructure planning; infrastructure charges, policy and schedules; growth management; process assessment; research and development; and regional planning. There are significant implications of the WBKMS for improving current practices of infrastructure planning and management. The provision of demand and supply data from water and wastewater systems and households can assist system modelling through:

- Identifying leakage within households and in the distribution system;

- Providing real-time diurnal pattern data of water demands at a household level which will assist with understanding required supply quantities, storage needs, excess supply available for resale or distribution, and discharge volumes; and

- Providing better predictive models on wastewater system requirements (e.g. treatment processes, estuarine, marine and river impacts, etc.) through realtime end use data related to prior knowledge on the typical waste constitute materials associated with such uses.

The WBKMS can improve infrastructure planning through: 
- Better modelling of water and wastewater systems and improved identification of upgrade requirements for stressed infrastructure;

- A comprehensive understanding of the expandability of a particular region (with existing infrastructure) and management of growth based on water demands; and

- Effective priority infrastructure planning and regional planning.

The data from a WBKMS will also provide significant insight into the development and effectiveness of water demand management strategies at the development scale.

\section{Water demand management}

Water demand management (WDM) is defined as the practical development and implementation of strategies aimed at reducing demand (Savenije and van der Zaag, 2002). The five categories of WDM include: (1) engineering, i.e. installing efficient showerheads or washing machines; (2) economics, i.e. water pricing; (3) enforcement, i.e. water restrictions; (4) encouragement, i.e. rebate programs for water efficient clothes washers: (5) and education, i.e. promoting water saving practices such as shorter showers (Gold Coast City Council, 2005). The application of a WBKMS could significantly improve on current decision making relating to the development of WDM strategies as well as provide empirical verification on achieved water savings from already implemented programs. The application of real-time end use data, for both water authorities and consumers, will undoubtedly revolutionise the current ad-hoc approach to WDM. Some of the benefits of a WBKMS for enhancing current demand management functions include the following:

- The ability to monitor the effect of enforcement or restriction levels on water consumption;

- The ability to immediately quantify the effect of targeted education programs (e.g. for particular demographics, shower time, rebate program, etc.) on their intended water end use(s);

- The capacity to establish the water savings resulting from implemented engineering applications such as efficient water appliances (e.g. washing machines, shower roses, etc.) and pressure and leakage management;

- The provision of real time water consumption data provided to water users/customers resulting in an increased level of knowledge and understanding of personal water consumption and how this compares with others; 
- A tool for definitive financial analysis of the cost and water saving benefits of implemented WDM programs, ultimately driving a least cost planning agenda; and

- Easy identification of leakage in households or businesses.

The WBKMS will allow for the instantaneous quantification of the effect of WDM strategies on water consumption. This will lead to significant improvement on the development and delivery of such measures, thus closing the loop on demand management strategies.

\section{Water customers}

The current metering and billing system only provides a single water consumption data figure to customers on their water bill or rates notice. The WBKMS provides a platform for extensive knowledge transfer of water consumption data, directly to consumers. The WBKMS will offer an easily accessible system which allows users to log on and see: where and when they are consuming water; how they are consuming on a per capita basis; how their consumption compares with others of a similar demographic makeup; information on current water restriction levels; and allocations (i.e. regulated water target split to end uses) and tips on how to reduce water consumption in areas and periods of high use. Users will be directed to pay their water bill through the WBKMS thus providing the need for people to use the system which instigates an understanding of how consumption behaviour translates into charges on their water bill. The functionality requirements for customers for the WBKMS include the following:

- Users logging on to their water company's web sites with their specific login and password for their property (water account). The screen will then take them to a Welcome Page that provides a water use summary for their property;

- The summary of water use includes water used yesterday, last week, quarter, year to date and associated costs. A summary of developed end use reports for each week, quarterly period, etc. will also be available;

- Users can compare their use with the 'average' or 'usual' end use consumption in their region in relation to households with a comparative makeup and a similar demographic situation (once this type of private information is consensually entered into the system by householders);

- If there are situations where a household is using above average volumes of water in a specified end use (e.g. clothes washing) they will be provided with 
some recommendations/downloadable fact sheets on ways to reduce consumption in that area (i.e. clothes washer - rebate; shower - efficient shower rose; etc.);

- The current water restriction levels set by local authority; and

- The reports and recommendations could also provide cost implications over a particular timeframe for reducing water in their home.

The provision of such a system will help consumers take a higher degree of ownership of their water use instead of the water utility or government. Ultimately the proposed WBKMS will be a valuable tool for knowledge and awareness transfer to users, allowing for the current level of government regulation and enforcement to be reduced over time.

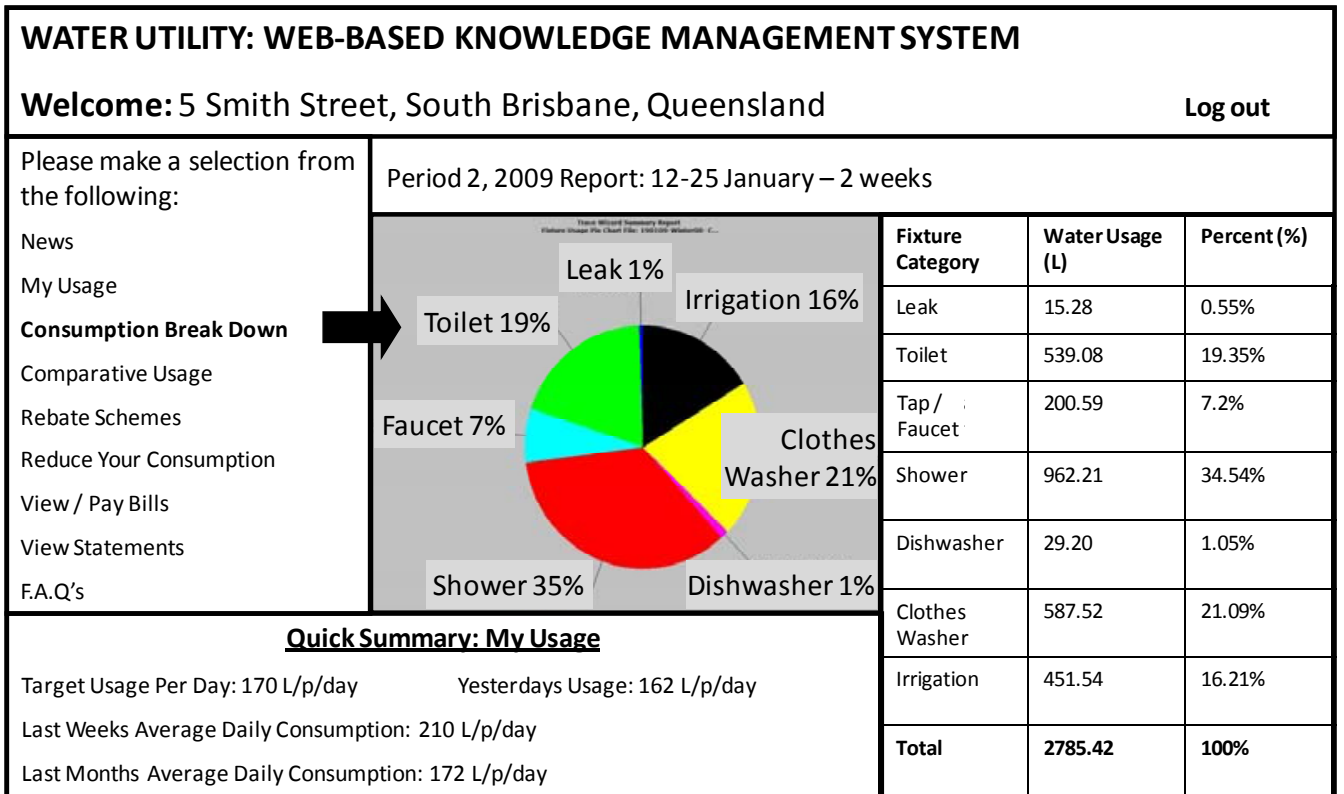

Figure 7Figure 7 shows an illustrative example of the potential output achievable from the customer interface.

[Insert Figure 7]

\section{FURTHER DEVELOPMENT AND IMPLEMENTATION}

The proposed WBKMS can be achieved with the current level of metering, data logging, data transfer technology, information systems, as well as some adopted techniques from the artificial intelligence area. However, there are still a number of impediments to achieving a tried and tested system suitable for the water industry. Such barriers, which have informed the below described research agenda include: 
- Creating robust wireless sensor networks. These wireless sensor networks must be able to transfer thousands of data points a day back to a remote server for all Australian homes. While the networks are available, issues with respect to wireless network reliability, black spots, power source, damage by users, water proofing and cross connections need to be resolved;

- Information systems that can collect and store water end use information. Servers capable of collecting all data in a logical manner for analysis are essential;

- Automated and reliable processing of flow traces into end use data categories. The development of pattern matching algorithms can achieve highly accurate categorisation once development and training, with end use data sets of a number of different households, has been completed. This is the most critical impediment requiring urgent research attention as the current approach to water end use analysis requires time consuming manual processing;

- Development of automated reporting tools that utilise processed information to create tailored reports for individual or groups of households at the request of the water utility and/or user; and

- Development of a user friendly web-based interface so required information that can be accessed by the water utility or individual user.

Another important issue that should be addressed is the current high economic costs associated with the implementation and maintenance of the proposed WBKMS, with the most significant costs being for the high resolution water meters and data loggers. Further research that investigates both short and long term cost implications of WBKMS is required to help develop an adequate implementation scheme that provides the balance between the benefits of the system and the capacity of the users to absorb the additional financial costs of such a system. This financial analysis is an ever changing dynamic as the cost of required smart metering technologies becomes exponentially cheaper with time, reliability improves as issues are addressed, data transfer costs reduce, and advanced management approaches become proven through applied research. Indeed, the development of a WBKMS for the planning and management of water services will need to encompass and consider all stakeholders in an integrated manner. Integration of all stakeholders is essential not only for water but for energy and other utilities as stakeholder roles overlap (Figure 8). Currently, water and energy end use studies are often initiated independently (e.g. those planned for Melbourne in 2010). A national coordinated approach, integrating energy and water smart metering, could build on existing 
frameworks such as the National Smart Metering Program (Australia) ${ }^{3}$, which currently has a focus on electricity. The integration and development of innovative, all inclusive data management tools such as the WBKMS will provide the required platform for the most sustainable and sensible use of precious water and energy resources.

\section{[Insert Figure 8]}

\section{CONCLUSION}

This paper has shown how the contemporary changes occurring in water planning, including a focus on efficient use and leak detection at the household and development scale, could be improved through smart metering to more effectively realise their water saving potential. Introducing smart water metering on a wide-scale necessitates the development of a WBKMS to interface with both the customer and utility, and to process the collected data into valuable information for water management and urban planning. Current research in the smart metering and end use fields demonstrates the need for the development of a WBKMS. The creation of such a system poses significant benefits for infrastructure planners, WDM managers, architects and developers who seek to better understand water consumption patterns. The system also provides comprehensive information to users which will vastly improve their current level of knowledge and understanding of their water consumption, thus enabling them to proactively address and control their consumption levels. The development of a WBKMS could ultimately lead towards more informed infrastructure planning, strategically developed and monitored WDM strategies and a significant improvement in awareness of where, when and how water is being used, by both water utilities and consumers.

\section{REFERENCES}

Birrell, B., Rapson, V. and Smith, F. (2005). Impact of Demographic Change and Urban Consolidation on Domestic Water Use, Water Services Association of Australia Inc., Melbourne.

Britton, T., Cole, G., Stewart, R. and Wisker, D. (2008). Remote diagnosis of leakage in residential households. Water: Journal of the Australian Water Association, 35(6): 89-93.

\footnotetext{
${ }^{3}$ http://share.nemmco.com.au/smartmetering/default.aspx
} 
Chambers, V.K., Creasey, J.D., Glennie, E.B., Kowalski, M. and Marshallsay, D. (2005). Increasing the value of domestic water use data for demand management summary report, WRc plc, Wiltshire.

Gold Coast City Council (2005). Gold Coast Waterfuture Project Overview. Gold Coast.

Hauber-Davis, G. and Idris, E. (2006). Smart Water Metering. Water: Journal of the Australian Water Association, 33(3): 56-59.

Hydroshare (2009). New Hydroshare System. Accessed October 2009 http://www.usus.com.au/usutility/display.asp?entityid=3208

Idris, E. (2006). Smart metering: a significant component of integrated water conservation system, Proceedings of the 1st Australian Young Water Professionals Conference. International Water Association, Sydney.

Inman, D. and Jeffrey, P. (2006). A review of residential water conservation tool performance and influences on implementation effectiveness. Urban Water Journal, 3(3): 127 - 143.

IPART. (2008). Overview of licensing under the Water Industry Competition Act 2006. WICA Fact Sheet, Independent Pricing and Regulatory Tribunal NSW, August 2008.

Loh, M. \& Coghlan, P. (2003). Domestic Water Use Study. Perth, Water Corporation.

Marvin, S., Chappells, H. and Guy, S. (1999). Pathways of smart metering development: shaping environmental innovation. Computers, Environment and Urban Systems 23(2): 109-126.

McIntyre, T. J. (2008). Data retention in Ireland: Privacy, policy and proportionality. Computer Law \& Security Report 24(4): 326-334.

Neenan, B. and Hempill, R. (2008). Social benefits of smart metering investments. The electricity journal. 21(8): 32-45.

NYSERDA (2003). A Primer on Smart Metering. New York State Energy Research and Development Authority. Available online at: http://sites.energetics.com/madri/toolbox/pdfs/background/primer.pdf.

Savenije, G. H. H. \& van der Zaag (2002). Water as an economic good and demand management: paradigms and pitfalls. Water International, 27(1), 98-104.

Willis, R., Stewart, R.A., Panuwatwanich, K., Capati, B. and Giurco, D. (2009). Gold Coast Domestic Water End Use Study. Water: Journal of Australian Water Association. 36(6): 79-85. 


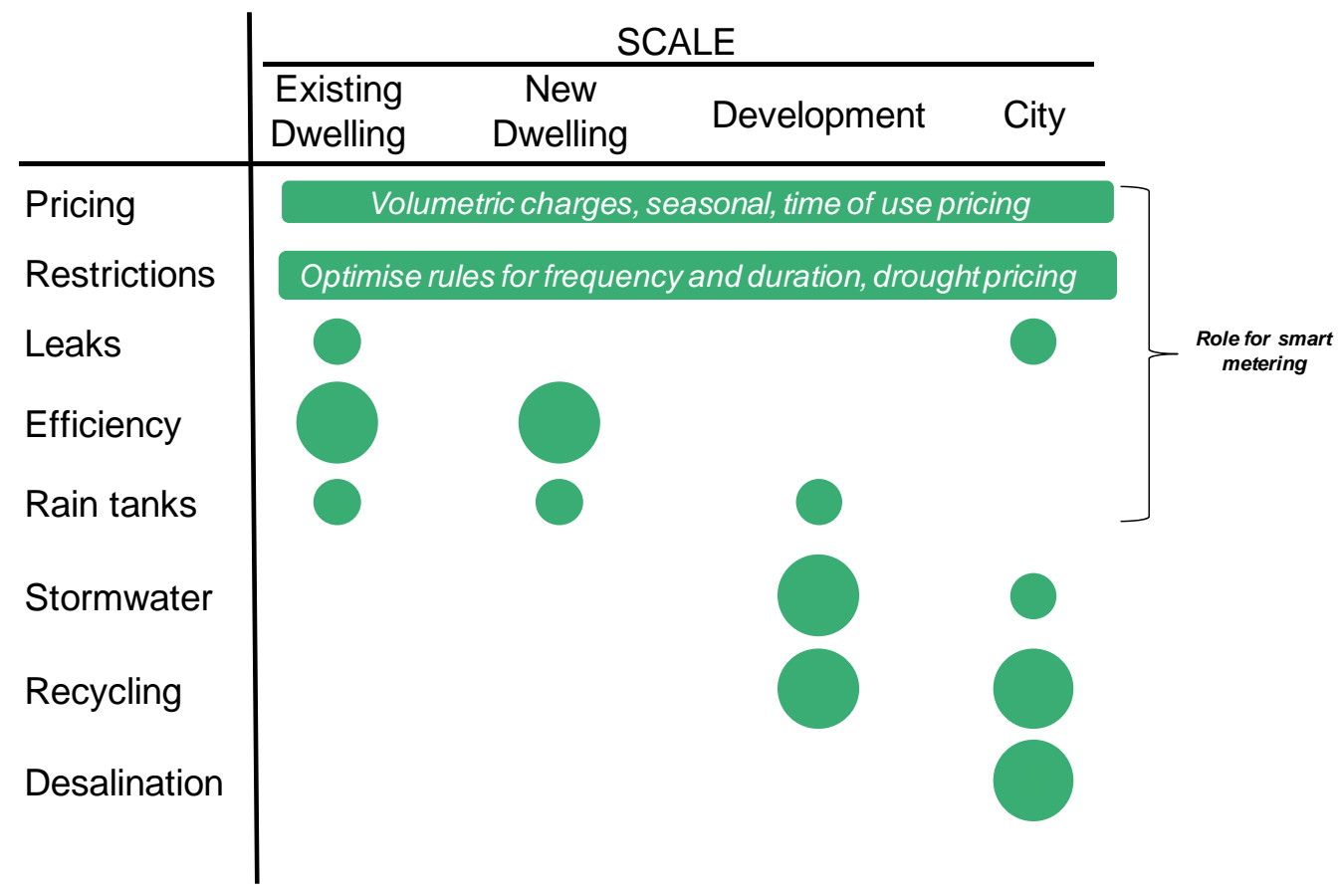

Figure 1: Potential for demand reduction and alternative supply options across scales

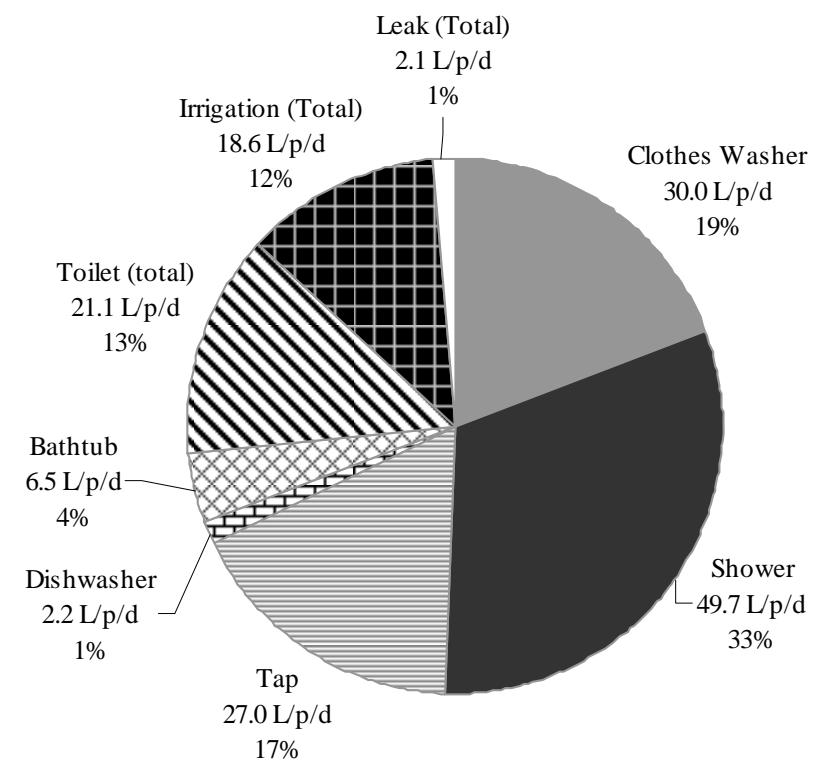

Figure 2: End use break down, Gold Coast (winter pre-retrofit) (Willis et al. 2009) 

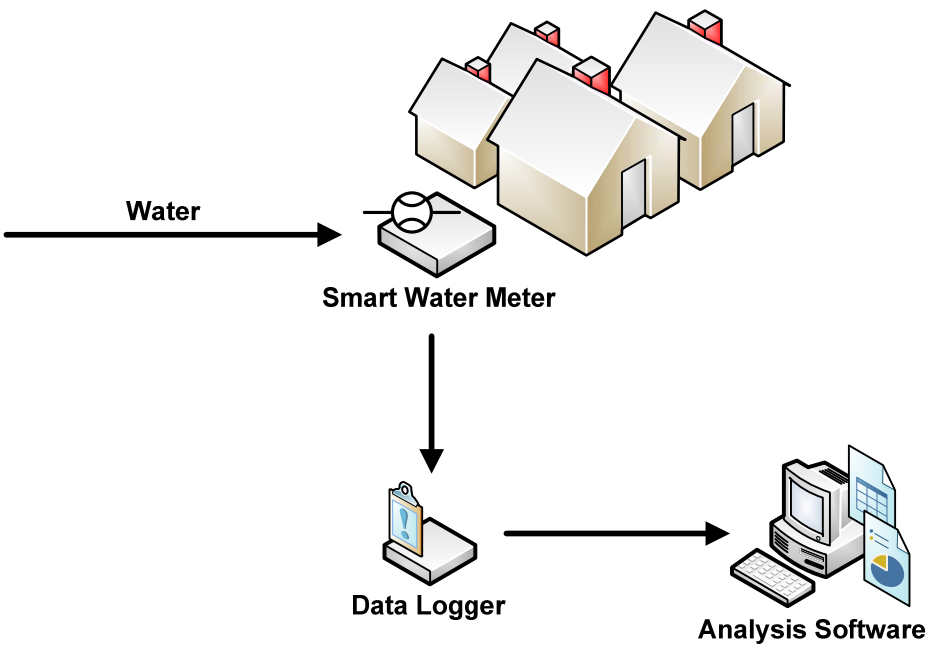

Figure 3: Typical smart meter set up in residential household

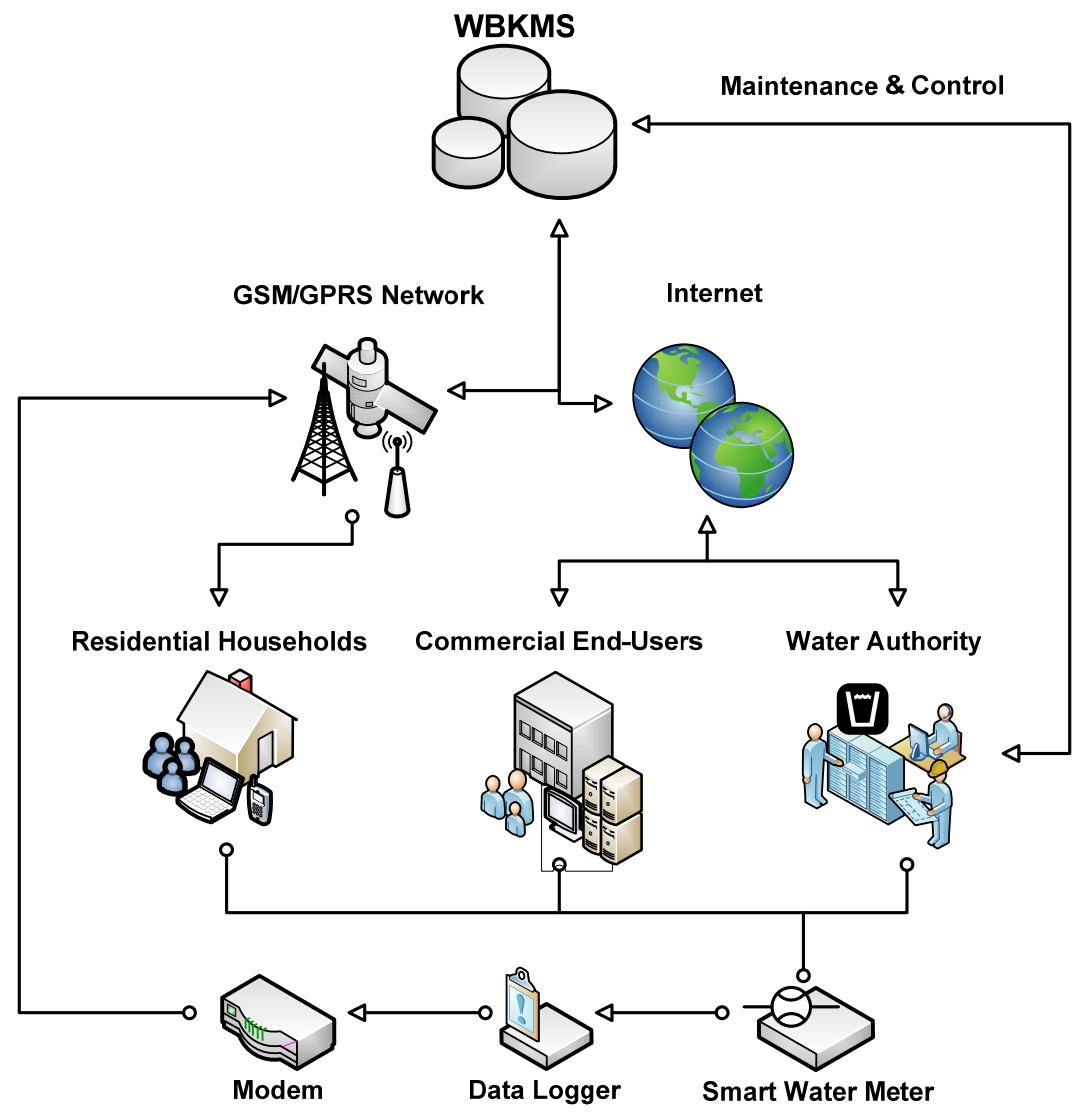

Figure 4: Structure of the Web-Based Knowledge Management System 


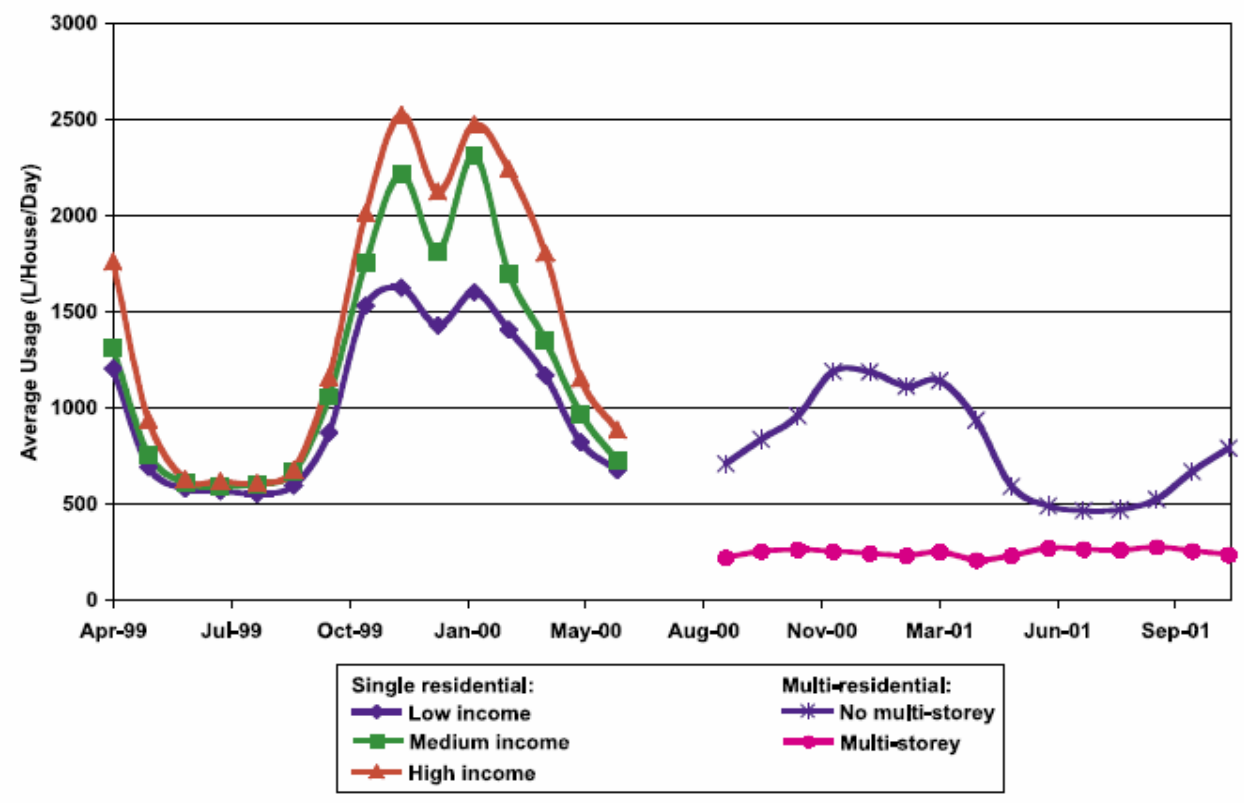

Figure 5: Average monthly usages of different households (Loh and Coghlan, 2003)

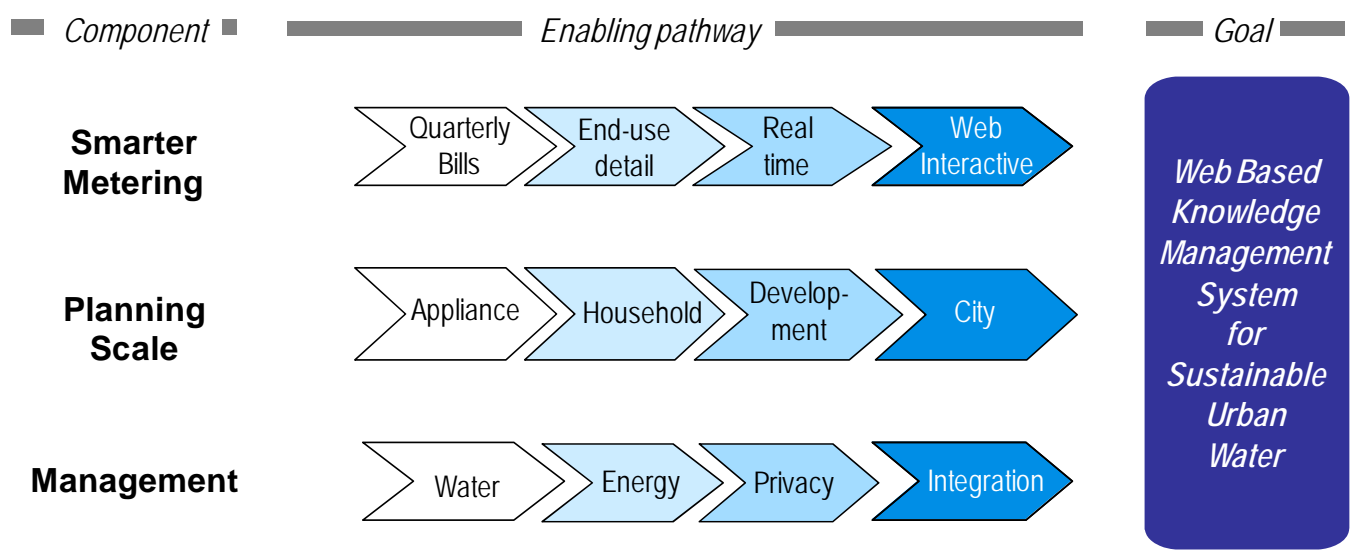

Figure 6: Role of smart metering in management and planning across scales 


\section{WATER UTILITY: WEB-BASED KNOWLEDGE MANAGEMENT SYSTEM}

Welcome: 5 Smith Street, South Brisbane, Queensland

Log out

Please make a selection from

the following:

News

My Usage

Consumption Break Down

Comparative Usage

Rebate Schemes

Reduce Your Consumption

View / Pay Bills

View Statements

F.A.Q's

Period 2, 2009 Report: 12-25 January - 2 weeks

Fixture

\begin{tabular}{|l|l|l|}
\hline $\begin{array}{l}\text { Fixture } \\
\text { Category }\end{array}$ & $\begin{array}{l}\text { Water Usage } \\
\text { (L) }\end{array}$ & Percent (\%) \\
\hline Leak & 15.28 & $0.55 \%$ \\
\hline Toilet & 539.08 & $19.35 \%$ \\
\hline $\begin{array}{l}\text { Tap/ } \\
\text { Faucet }\end{array}$ & 200.59 & $7.2 \%$ \\
\hline Shower & 962.21 & $34.54 \%$ \\
\hline Dishwasher & 29.20 & $1.05 \%$ \\
\hline $\begin{array}{l}\text { Clothes } \\
\text { Washer }\end{array}$ & 587.52 & $21.09 \%$ \\
\hline Irrigation & 451.54 & $16.21 \%$ \\
\hline Total & $\mathbf{2 7 8 5 . 4 2}$ & $\mathbf{1 0 0 \%}$ \\
\hline
\end{tabular}

Figure 7 WBKMS water customer interface illustrative example

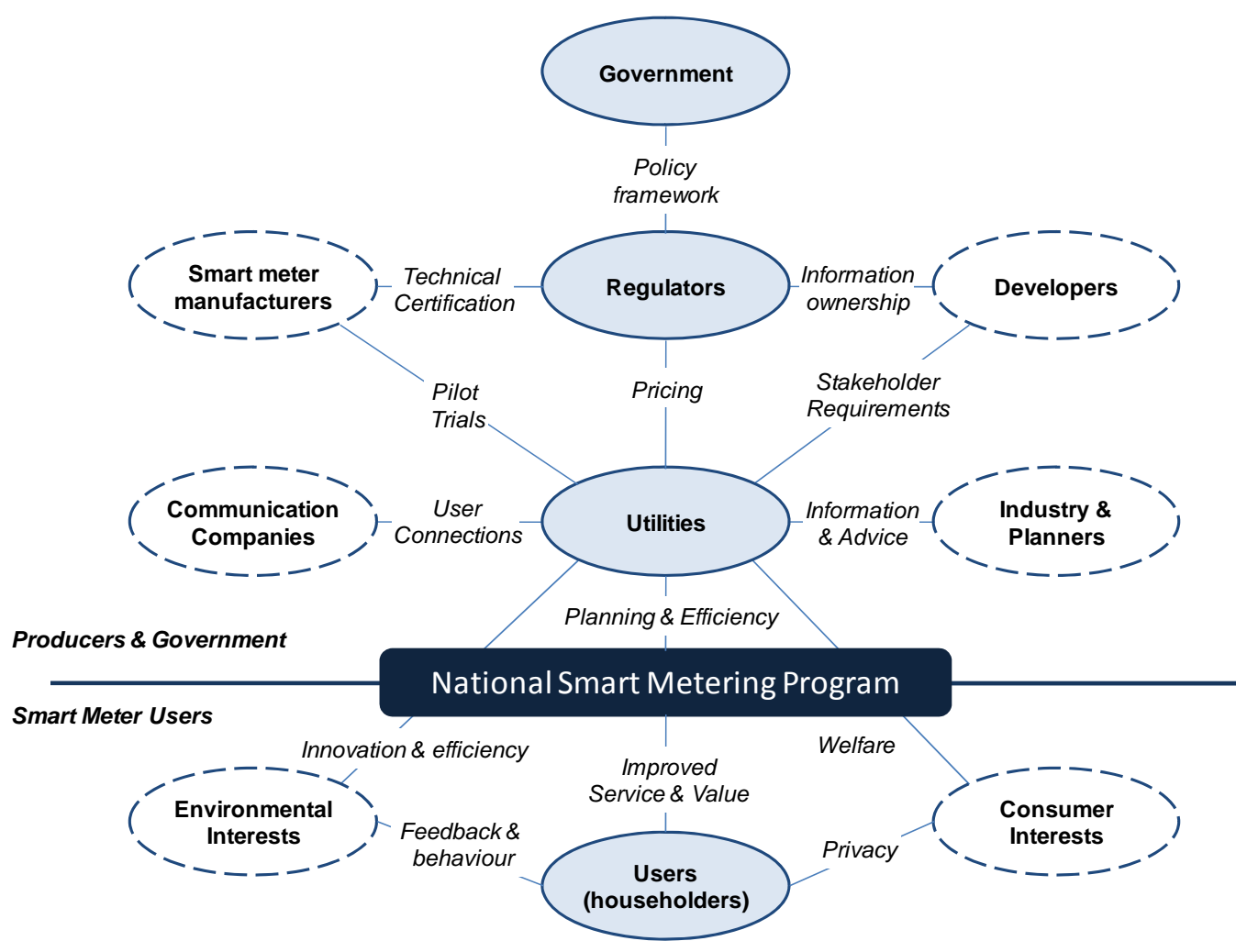

Figure 8: Producer and user roles (after Marvin et al., 1999) 